Pak. J. Anal. Environ. Chem. Vol. 19, No. 2 (2018) 153 - 159

\title{
Microwave Assisted Urea Modified Bengal Gram Husk for the Batch Wise Removal of Methylene Blue from Aqueous Medium
}

\author{
Amara Dar ${ }^{1 *}$, Iram Riaz ${ }^{2}$ and Jamil Anwar ${ }^{3}$ \\ ${ }^{1}$ Center for Undergraduate Studies, University of the Punjab, 54590, Lahore, Pakistan. \\ ${ }^{2}$ Queen Marry College, Lahore, Pakistan. \\ ${ }^{3}$ Comsats Institute of Information Technology, Lahore, Pakistan. \\ *Corresponding Author Email: a_dar_2@hotmail.com \\ Received 13 August 2018, Revised 26 November 2018, Accepted 28 November 2018
}

\begin{abstract}
Effluents from industries directly pollute water bodies as a result the drinking water sources are contaminated. In present study, removal of methylene blue from aqueous medium by using raw bengal gram husk (RBGH) and microwave assisted urea modified Bengal gram husk (UMBGH) was done. Effect of different parameters such as contact time, shaking speed, adsorbent dose, temperature, $\mathrm{pH}$ were studied. Mechanism of adsorption was revealed using Langmuir, Freundlich and Temkin adsorption model. Experimental data followed the Langmuir adsorption isotherm that is revealed from the $\mathrm{R}^{2}$ values and adsorption capacity $\left(\mathrm{q}_{\max }\right) 7.915 \mathrm{mg} \mathrm{g}^{-1}$ and $111.178 \mathrm{mg} \mathrm{g}^{-1}$ for both RBGH and UMBGH, respectively. The value of " $n$ " was 1.001 and 0.979 for RBGH and UMBGH which indicated that adsorption was favorable. $\mathrm{B}_{\mathrm{T}}$ value of RBGH and UMBGH was 5.784 and 4.093, respectively which revealed that adsorption was physical in nature. Present study proved that microwave assisted urea modification of Bengal gram husk greatly increased the removal efficiency of the adsorbent.
\end{abstract}

Keywords: Methylene Blue, Bengal Gram Husk, Urea Modification, Microwave Assisted, Adsorption.

\section{Introduction}

Dyes are ionizing, colored, complex aromatic compounds and possess high ability to resist biodegradation. Dyes are classified into acidic, basic, disperse, azo, anthraquinone. Even at a very low concentration of dye in water is visible; it decreases sunlight penetration in water as a result aquatic life is infected. In world more than $7 \times 10^{5}$ tonnes/annum dyes are produced and industries consumes more than $10^{7} \mathrm{~kg} /$ annum dye $[1,2]$. Consumption of dyes in industries increased pressure on the availability of potable water resources. Industrial effluents contained a million gallons of dye, which is discharged directly into water streams without any adequate treatment. Usually paper, pulp, textile, cosmetics, pharmaceutical, leather, tanning, dye synthesis, food and plastic industries used a large amount of dyes. Dyes are complex aromatic compounds and possess high ability to resist biodegradation. Even at a very low concentration of dye in water is visible; it decreases sunlight penetration in water as a result aquatic life is infected.

Methylene blue (MB) is one of toxic industrial dye, its removal from water is very important. Major sources of $\mathrm{MB}$ dye are the effluents of hospitals, laboratories, industries such as pharmaceutical, pulp and paper, textile, paint, cosmetics. MB concentration in water is responsible for diseases such as dyspnea, cyanosis, 
convulsion, methemoglobinemia, skin irritation, gastrointestinal tract irritation, nausea, vomiting, and diarrhea, Heinz body formation, shock, cyanosis, jaundice [3].

Different methods such as physical method (like reverse osmosis), chemical method (like ion-exchange) and adsorption could be applied for the removal of dyes but it was found that biosorption process is cheap, efficient, simple, eco-friendly, effective and economic for the removal of $\mathrm{MB}$ dye [4]. Some biosorbents had been used for the removal of $\mathrm{MB}$ from aqueous medium are listed in Table 1.

Table 1. Comparison of Sorption Capacity of Biosorbent for Methylene blue.

\begin{tabular}{|c|c|c|c|}
\hline Adsorbent & Dye & $Q_{\max }$ & Reference \\
\hline Haloxylon recurvum stem & MB & $22.93 \mathrm{mg} / \mathrm{g}$ & [1] \\
\hline Oil palm fiber & MB & $312.5 \mathrm{mg} / \mathrm{g}$ & [5] \\
\hline Oil palm fiber & MB & $53.1 \mathrm{mg} / \mathrm{g}$ & [6] \\
\hline Rice husk & MB & $40.58 \mathrm{mg} / \mathrm{g}$ & [7] \\
\hline $\begin{array}{l}\text { Parthenium hystrophorous } \\
\text { Weed }\end{array}$ & MB & $23.8 \mathrm{mg} / \mathrm{g}$ & {$[8]$} \\
\hline Raw Bengal Gram Husk & MB & $7.915 \mathrm{mg} / \mathrm{g}$ & $\begin{array}{l}\text { Present } \\
\text { Study }\end{array}$ \\
\hline $\begin{array}{l}\text { Urea Modified Bengal } \\
\text { Gram Husk }\end{array}$ & MB & $111.178 \mathrm{mg} / \mathrm{g}$ & $\begin{array}{l}\text { Present } \\
\text { Study }\end{array}$ \\
\hline
\end{tabular}

Moreover Bengal gram (Cicer arientinum $L)$ is widely used in food, medicine, dye and adsorbent for the sorption of toxic contaminants as heavy metals and dyes. In past few years bengal gram husk (BGH) has been used as adsorbent for the removal of various dyes as congo red, rhodamine $\mathrm{B}$, acid blue 25(AB) [9, 10]. Heavy metal removal has also been done using modified form of this husk as an adsorbent [11].

Therefore, main aim of this study is to explore the binding sites of $\mathrm{BGH}$ by microwave activation with urea. Raw and microwave assisted urea modified $\mathrm{BGH}$ is used in present study for the solid phase adsorptive removal of $\mathrm{MB}$ from aqueous medium. Comparative analysis tells about the increased functionality of modified husk under the effect of microwaves. Adsorbent is characterized by FT-IR and SEM in order to explore the effect of microwave assisted treatment.

\section{Materials and Methods Chemicals and equipment}

MB dye (Mol. wt. $319.85 \mathrm{~g} / \mathrm{mol}$, WINLAB) used as adsorbate in the present study. It is cationic in nature having heterocyclic structure; its chemical formula as $\mathrm{C}_{16} \mathrm{H}_{18} \mathrm{~N}_{3} \mathrm{SCl}$ is shown in Fig. 1.<smiles>CN(C)c1ccc2nc3ccc(N(C)C)cc3[s+]c2c1</smiles>

Figure 1. Molecular structure of Methylene blue

$\mathrm{MB}$ is very toxic dye. Its removal from water is very important. MB solution $(1000 \mathrm{mg} / \mathrm{L})$ was prepared and diluted according to the requirement for batch study. $\mathrm{HCl}, \mathrm{NaOH}$ (MERK) solution $(0.1 \mathrm{M})$ was prepared for $\mathrm{pH}$ study. Glassware was washed with deionized water and dried in oven for use. $\mathrm{pH}$ meter (InoLab pH 720) was used to measure $\mathrm{pH}$, orbital shaker (Yellow line) was used for shaking solution. Spectrophotometer (HITACHI, U-1800) was used for absorbance measurement. Microwave oven (Dawlance, 2,450 MHz) was used for irradiation of adsorbent.

\section{Preparation of biosorbent and characterization of adsorbent}

Bengal gram raw material was collected from a local market of Lahore. It was washed and dried. It was crushed and sieved to 60 ASTM. Powdered mass was stored in air tight jar. It was designated as raw Bengal gram husk (RBGH). Urea and a part of RBGH were taken (1:1) and exposed to microwaves (Dawlance: 2,450 MHz) for 12 minutes by following procedure of earlier research with little modifications [12, 13]. Obtained mass was boiled in distilled water for 30 minutes to remove excess urea content and colored impurities and was filtered out. Material was then dried in oven at $70{ }^{\circ} \mathrm{C}$ for 24 hours. Dried mass was termed as urea modified Bengal gram husk (UMBGH), it was stored in air tight plastic bottle and used for further adsorption study. RBGH and UMBGH were subjected to FT-IR analysis. Appearance of various bands showed the presence of nitrogen. After modification slight shifts in bands have been observed. Moreover, the shifts 
showed the formation of secondary amides on surface of BGH which favors the increase in the binding sites on the surface of adsorbent thereby making it more functional in terms of dye removal.

\section{Batch mode experiment}

Using RBGH and UMBGH as adsorbents optimization of experimental parameters (adsorbent dose, contact time, shaking speed, temperature and $\mathrm{pH}$ ) were carried out at initial dye concentration of $25 \mathrm{ppm} / 50 \mathrm{~mL}$. Factors such as contact time (5-70 min.), shaking speed (50-450 $\mathrm{rpm})$, adsorbent dose (0.1-1.1 g), temperature (283.0-333.0 K), pH (3-11) were studied one by one and other factors were kept constant for RBGH and UMBGH in the batch experiment. Removal efficiencies (\%) of RBGH and UMBGH were studied by using spectrophotometer $(\lambda=663 \mathrm{~nm})$. Maximum absorbance wavelength $\left(\lambda_{\max }\right)$ was measured by using UV-Vis spectrophotometer (U1800 , HITACHI) by using $10 \mathrm{mg} / \mathrm{L}$ solution of methylene blue at different wavelength.

\section{Equilibrium isothermal study}

Freundlich, Langmuir, Temkin isotherms were used to evaluate the equilibrium of the process. Linear equation of Langmuir, Freundlich and Temkin isotherms [14] were given in equation (a, b, c), respectively.

$\mathrm{q}_{\mathrm{e}}=\mathrm{q}_{\max } \cdot \mathrm{b} \cdot \mathrm{C}_{\mathrm{e}} / 1+\mathrm{b} \cdot \mathrm{C}_{\mathrm{e}}$

$\mathrm{C}_{\mathrm{e}}(\mathrm{mg} / \mathrm{L})$ is equilibrium concentration of dye solution, $\mathrm{q}_{\mathrm{e}}(\mathrm{mg} / \mathrm{g})$ is amount of dye sorbed at equilibrium, $\mathrm{q}_{\max }(\mathrm{mg} / \mathrm{g})$ is monolayer capacity of adsorbent, $\mathrm{K}_{\mathrm{L}}$ is Langmuir adsorption constant.

$\mathrm{q}_{\mathrm{e}}=\mathrm{K}_{\mathrm{F}} \cdot \mathrm{C}_{\mathrm{e}} \cdot{ }^{1 / n}$

$\mathrm{K}_{\mathrm{F}}$ and $\mathrm{n}$ are Freundlich constants, $\mathrm{q}_{\mathrm{e}}$ is adsorption capacity $(\mathrm{mg} / \mathrm{g})$

$\mathrm{Qe}=\mathrm{BT} \cdot \ln \mathrm{KT}$.Ce

$\mathrm{B}_{\mathrm{T}}$ and $\mathrm{K}_{\mathrm{T}}$ are Temkin constants

\section{Thermodynamic study}

Temperature is one of the important parameter to study the adsorption process. Data obtained from temperature studied is used to calculate $\Delta \mathrm{S}^{\circ}, \Delta \mathrm{H}^{\circ}, \mathrm{T} \Delta \mathrm{S}^{\circ}[5]$.
$\Delta \mathrm{S}^{\circ}=\Delta \mathrm{H}^{\circ}-\mathrm{T} \Delta \mathrm{S}^{\circ}$

$\Delta \mathrm{G}^{\circ}$ is standard Gibb's free energy

$\Delta \mathrm{G}^{\circ}=-\mathrm{RT} \ln \mathrm{K}$

$\mathrm{K}_{\mathrm{d}}=\mathrm{q}_{\mathrm{e}} / \mathrm{C}_{\mathrm{e}}$

$\Delta \mathrm{H}^{\circ}$ is change in standard enthalpy, $\Delta \mathrm{S}^{\circ}$ is change in standard entropy.

\section{Results and Discussion \\ Characterization of BGH and UMBGH}

FTIR spectra of RBGH and UMBGH are shown in Fig.2a, Fig. 2b. FTIR study indicated that spectral bands of RBGH after urea modification shifted from $1027 \mathrm{~cm}^{-1}, 1052 \mathrm{~cm}^{-1}, 1100 \mathrm{~cm}^{-1}$ to $1031 \mathrm{~cm}^{-1}, 1053 \mathrm{~cm}^{-1}, 1105 \mathrm{~cm}^{-1}$ in aliphatic amines. Bands appeared at $1316 \mathrm{~cm}^{-1}$ shifted to $1317 \mathrm{~cm}^{-1}$ in aromatic amines. Bands appeared at $1422 \mathrm{~cm}^{-1}$ shifted to $1418 \mathrm{~cm}^{-1}$ in aromatics. Bands $1157 \mathrm{~cm}^{-1}$ and $1603 \mathrm{~cm}^{-1}$ were missing after modification and additional bands appeared at $1234 \mathrm{~cm}^{-1}$ showed the presence of $\mathrm{C}-\mathrm{N}$ bond stretching in aliphatic amines. Bands at $1697 \mathrm{~cm}^{-1}$, $1701 \mathrm{~cm}^{-1}$ showed the presence of $\mathrm{C}=\mathrm{O}$ bond in alpha, beta unsaturated aldehyde, ketone.
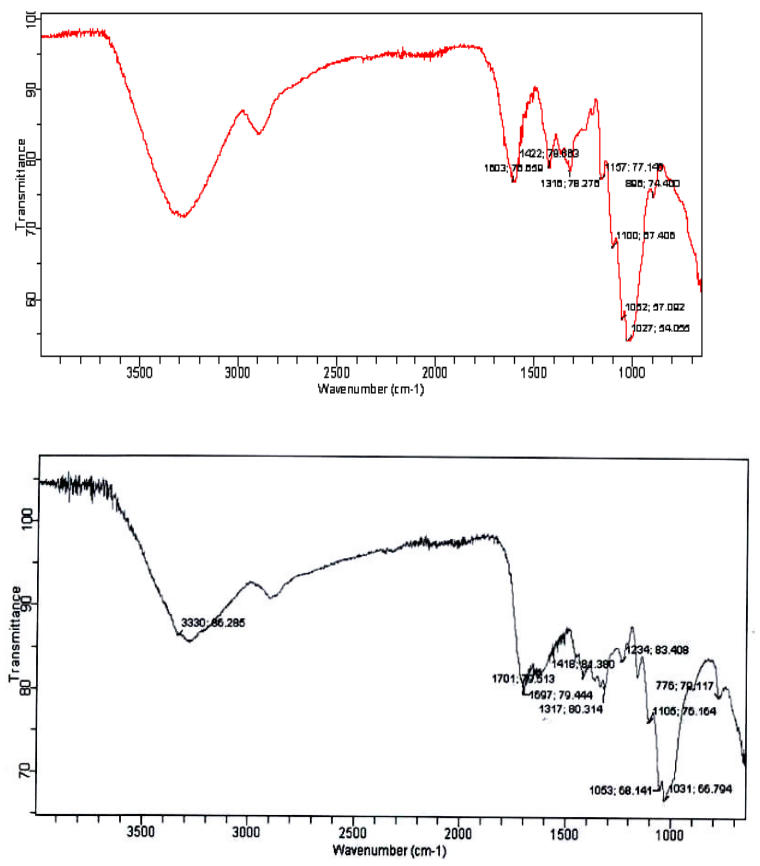

Figure2. FT-IR spectra of RBGH (before) and UMBGH (after) Urea modification 
SEM micrographs of RBGH and UMBGH are shown in Fig. 3a, Fig. 3b. Particles of RBGH are large in size and has rough surface which had been revealed from the SEM images of RBGH as shown in Fig. 3a. After microwave activation of BGH with urea it is noted that the surface area of particles increased and it had rough surface. Several cervices and holes had been seen on the surface of UMBGH. After microwave activation with organic compound urea holes has created on the adsorbent surface. Organic compounds are volatile and when adsorbent was irradiated, several molecules of urea decomposed and with the release of carbon dioxide gas, which created the holes on the surface of adsorbent. UMBGH may have large surface area proved by SEM images and in result adsorption capacity should be increased.


Figure 3. SEM Image before (RBGH) and after (UMBGH)

\section{Effect of shaking speed}

Experiments were conducted to monitor the effect of shaking speed $(50-450 \mathrm{rpm})$ on MB removal for RBGH and UMBGH. It was observed that removal of $\mathrm{BB}$ increased with increased in shaking speed. Maximum removal efficiency (\%) was observed at $400 \mathrm{rpm}$ in case RBGH and at 300 rpm in case of UMBGH. High shaking speed distributed adsorbent in MB solution evenly and greater number of active sites were available whereas in case of low agitation speed adsorbent aggregates and active sites were not available. The trend of removal efficiency (\%) of adsorbent with agitation speed is shown in Fig. 4.

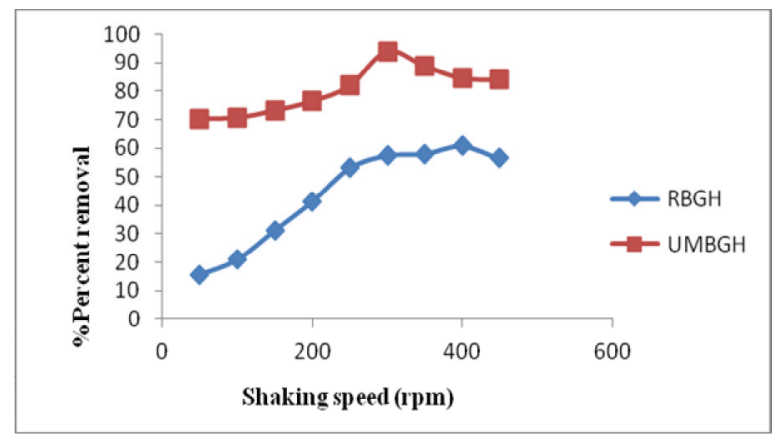

Figure 4. Effect of shaking speed (rpm) on MB removal onto RBGH and UMBGH. Adsorbent dose (0.1 g), Time (30 min.), Solution concentration ( $25 \mathrm{ppm} / 50 \mathrm{~mL})$, Temperature $(293.0 \mathrm{~K})$

\section{Effect of contact time}

It is illustrated in Fig. 5 that removal efficiency (\%) of MB increased rapidly with the increased in contact time onto RBGH and UMBGH. A time period of 50 minutes is enough for the achievement of equilibrium. Removal efficiency (\%) of adsorbents did not change with the further increase in time, because all the active sites were occupied. Therefore, a contact time of 50 minutes was chosen for further study.

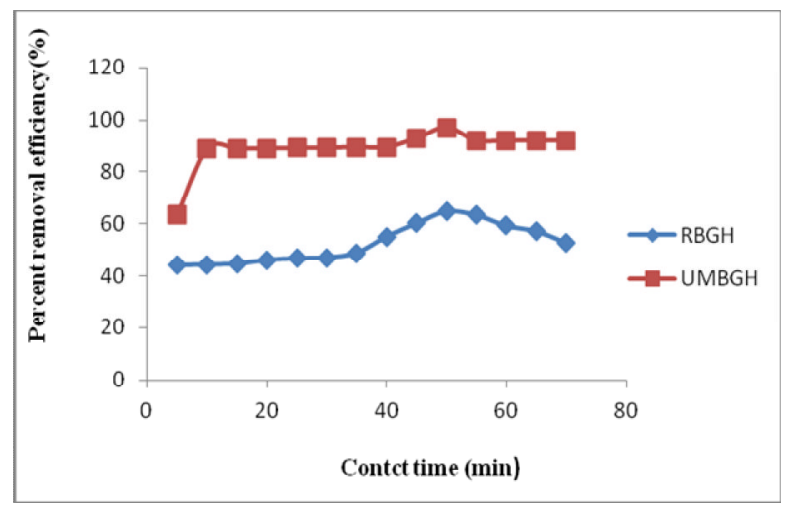

Figure 5. Effect of time (min.) on MB removal onto RBGH and UMBGH. Adsorbent dose (0.1 g), Shaking speed $(\mathrm{RBGH}=400$ rpm, UMBGH = 300 rpm), Solution concentration $(25 \mathrm{ppm} / 50$ $\mathrm{mL}$ ), Temperature ( $293.0 \mathrm{~K})$ 


\section{Effect of initial dye concentration isothermal} study

It was observed that removal efficiency of the adsorbent increased with the increased in concentration of dye. Adsorption isotherm is the study of adsorption equilibrium at given temperature. Langmuir, Freundlich, Temkin isotherm model were selected to show the capacity of RBGH and UMBGH for the removal of methylene blue.

Langmuir isotherm revealed that adsorbent is homogeneous and surface of adsorbent is uniformly energetic, maximum sorption capacity (q $\max$ ) of RBGH and UMBGH are $7.915 \mathrm{mg} \mathrm{g}^{-1}$ and $111.178 \mathrm{mg} \mathrm{g}^{-1}$, respectively. Increase in $\mathrm{q}_{\max }$ value in case of UMBGH indicates number of active sites increases after modification. Equilibrium parameter $\left(R_{L}\right)$ is calculated by using factor ' $b$ '. $\mathrm{R}_{\mathrm{L}}$ value indicated the reaction favorability and its values are 0.026 and 0.0345 for RBGH and UMBGH, respectively which indicated reaction was favorable.

Freundlich isotherm model were used to study the equilibrium data and the values of parameters are given in (Table 2). The shape of the graph is non-linear. The value of ' $n$ ' in range of 110 indicated the reaction favorability and its values for RBGH and UMBGH were 1.001 and 0.9675 , respectively. Value of $\mathrm{K}_{\mathrm{F}}$ expressed the adsorption capacity and its values were 5.702 and 10.16 for RBGH and UMBGH, respectively.

Equilibrium data was used to study the Temkin model and its parameters are given in Table 2. Temkin model provide data about the heat of adsorption and the interaction between adsorbent-adsorbate. The shape of the graph is non-linear. By studying different isothermal models it was investigated that adsorption data was better fitted with Langmuir isothermal model.

Table 2. Isothermal Parameters for MB adsorption.



\section{Effect of pH of solution}

The most important parameter which effects the removal of dye is $\mathrm{pH}$. It is shown in Fig. 6 that RBGH favor removal of dye in acidic medium ( $\mathrm{pH}$ 5) and UMBGH favor removal in neutral medium $(\mathrm{pH} 7)$. At high $\mathrm{pH}$ negative ions in solution increased and cationic dye (MB) trapped at the surface of modified adsorbent.



Figure 6. Effect of pH on MB removal onto RBGH and UMBGH. Adsorbent dose $(\mathrm{RBGH}=0.3 \mathrm{~g}, \mathrm{UMBGH}=0.7 \mathrm{~g})$, Shaking speed $($ RBGH $=400 \mathrm{rpm}, \mathrm{UMBGH}=300 \mathrm{rpm})$, Solution concentration ( 25 ppm / $50 \mathrm{~mL})$, Time (50 min.)

\section{Effect of adsorbent dose}

Adsorption of $\mathrm{MB}$ onto $\mathrm{RBGH}$ and UMBGH were studied by varying the adsorbents dose $(0.1-1.1 \mathrm{~g})$. It was observed that RBGH showed maximum adsorption at $0.3 \mathrm{~g}$ dos. Further increased in dose removal of $\mathrm{MB}$ was not observed. In case of UMBGH maximum adsorption takes place at $0.7 \mathrm{~g}$ dose, further increased in dose adsorption does not increases as shown in Fig 7. Adsorption capacity decreased with increased in adsorbent dose was due two factors: firstly due to concentration gradient which occurred between adsorbent and adsorbate secondly due to intraparticle attraction which decreased the surface area of adsorbent.

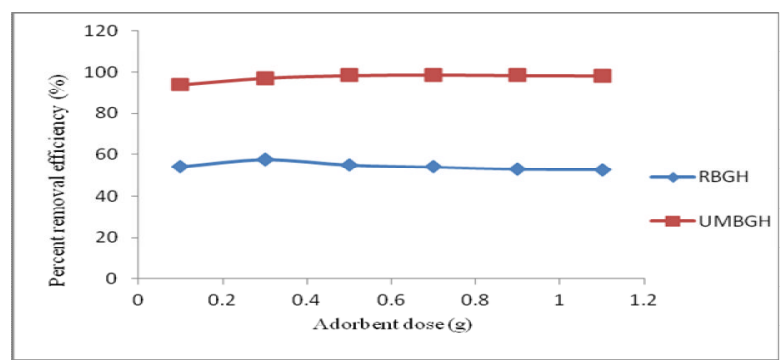

Figure 8 . Effect of adsorbent dose (g) on MB removal onto RBGH and UMBGH. Shaking speed $($ RBGH $=400 \mathrm{rpm}, \mathrm{UMBGH}=300$ rpm), Solution concentration ( $25 \mathrm{ppm} / 50 \mathrm{~mL})$, Time (50 min.), Temperature (293.0 K) 


\section{Thermodynamic study}

Temperature is one of the major factors to study the adsorption behavior. The investigated optimum temperatures for the removal of $\mathrm{MB}$ by using adsorbent RBGH and UMBGH was $293.0 \mathrm{~K}$ with removal efficiencies $66.6 \%$ and $96.85 \%$, respectively. Temperature ranged $(283.0 \mathrm{~K}-333.0$ $\mathrm{K})$ was applied. With the increased in temperature removal efficiency (\%) increased and attained equilibrium at $293.0 \mathrm{~K}$. Removal efficiency (\%) started decreasing after $293.0 \mathrm{~K}$ because at high temperature motion of $\mathrm{MB}$ molecules increased and contact time between adsorbent and adsorbate decreased. Influence of temperature on RBGH has great impact whereas UMBGH has no as such variation. Thermodynamic parameters were used to study the adsorption behavior; UMBGH was very efficient for the removal of dye as compared to RBGH. These parameters are enthalpy $\left(\Delta \mathrm{H}^{\circ}\right)$, standard free energy $\left(\Delta \mathrm{G}^{\circ}\right)$ and entropy $\left(\Delta \mathrm{S}^{\circ}\right)$ was calculated by following given formulas.

$\Delta \mathrm{G}^{\circ}=-\mathrm{RT} \ln \mathrm{K}^{\mathrm{D}}$

Calculated values of thermodynamics parameters are given in Table 3. Value of $\Delta \mathrm{G}^{\circ}$ showed that reaction was spontaneous and negative sign indicated the reaction feasibility. Value of $\Delta \mathrm{G}^{\circ}$ was high in case of UMBGH indicated adsorption was more favorable as compared to RBGH. Negative value of $\Delta \mathrm{H}^{\circ}$ indicated reaction was exothermic. Positive value of $\Delta S^{\circ}$ indicated binding forces impart randomness to the system. Due to urea modification of the adsorbent randomness of the binding sites increased.

Table 3. Thermodynamic parameters for MB adsorption.

\begin{tabular}{lcccc}
\hline Adsorbents & Temperature $(\mathbf{K})$ & $\Delta \mathbf{G}^{\circ}$ & $\Delta \mathbf{H}^{\circ}$ & $\boldsymbol{\Delta S}^{\circ}$ \\
\hline \multirow{3}{*}{ RBGH } & 283.0 & -11.8811 & -11.14 & 0.323 \\
& 293.0 & -11.4259 & & \\
& 303.0 & -12.0927 & & \\
& 313.0 & -12.3908 & & \\
& 323.0 & -12.7361 & & \\
\hline \multirow{4}{*}{ UMBGH } & 333.0 & -13.1175 & & \\
& 283.0 & -11.622 & -10.93 & 0.228 \\
& 293.0 & -11.0098 & & \\
& 303.0 & -11.5758 & & \\
& 313.0 & -11.8547 & & \\
& 323.0 & -12.0322 & & \\
& 333.0 & -12.3065 & & \\
\hline
\end{tabular}

\section{Conclusion}

Present study is relatively novel version of adsorption process. Microwave assisted urea modification of the adsorbent was studied which was further characterized by FTIR and SEM to see morphological changes. Adsorption onto the surface of Bengal gram husk increased by urea modification this is primarily due to the surface modification that increased the pore size and surface area thereby favoring the process of adsorption in urea modified adsorbent. Isothermal study revealed the 15 times increase in adsorption capacity of adsorbent after modification. Thermal feasibility of the process is also explored by applying the thermodynamics study. The process seemed to be exothermic with increased randomness of the system.

\section{References}

1. M. Mulugeta and B. Lelisa, Mod. Chem. Appl., 2 (2014).

http://dx.dio.org/10.4172/23296798.1000146.

2. L. S. Oliveira, A. S. Franca, T. M. Alves and S. D. Rocha, J. Hazard. Mat., 155 (2008) 507.

https://doi.org/10.1016/j.jhazmat.2007.11.093

3. A. M. M. Vargas, A. L. Cazetta, M. H. Kunita, T. L. Silva and V. C. Almeida, Chem. Eng. J., 168 (2011) 722. https://doi.org/10.1016/j.cej.2011.01.067

4. K. S. Mundhe, A. A. Bhave, R. C. Torane, N. R. Deshpande and R.V. Kashalkar, Orient J. Chem., 25 (2009) 953.

http://www.orientjchem.org/dnload/KSMund he-AA-Bhave-RCTorane-NRDeshpande/OJCV025I04P953-959.pdf

5. W. Hussan, U. Farooq, M. Ahmad, M. Athar and M. A. Khan, Arab. J. Chem. 8 (2013). http://dx.doi.org/10.1016/j.arabjc.2013.05.002

6. K. Y. Foo and B. H. Hameed, Chem. Eng. J., 166 (2011) 792.

https://doi.org/10.1016/j.cej.2010.11.019

7. I. A. W. Tan, B. H. Hameed and A. L. Ahmad, Chem. Eng. J., 127 (2011) 111. https://doi.org/10.1016/j.cej.2006.09.010

8. V. Vadivelan and K. V. Kumar, J. Coll. Interf. Sci., 286 (2005) 90. https://doi.org/10.1016/j.jcis.2005.01.007 
9. M. C. S. Reddy and V. Nirmala, Arabian J. Chem., 10 (2017) S2406.

https://doi.org/10.1016/j.arabjc.2013.09.002

10. M. C. S. Reddy, V. Nirmala and C. Ashwini, Arab. J. Chem., 10 (2017) S2554. https://doi.org/10.1016/j.arabjc.2013.09.029

11. D. Panhekar, Inter. J. Chem. Phys. Sci., 4 (special issue), (NCSC-2015), ISSN:2319$\underline{6602 .}$

12. O. Hamdaoui, J. Hazard Materials, B135, (2006) 264.

https://doi.org/10.1016/j.jhazmat.2005.11.062
13. M. Salman, M. Athar, U. Farooq, H. Nazir, A. Noor and S. Nazir, Korean J. Chem. Eng., 30 (2013) 1257. https://doi.org/10.1007/s11814-013-0054-3

14. M. Salman, M. Athar, U. Farooq, S. Rauf and U. Habiba, Korean. J. Chem. Eng., 31 (2014) 467.

https://doi.org/10.1007/s11814-013-0264-8 